\section{La dimérisation, une nouvelle propriété de I'ARN polymérase des virus influenza}

Catherine Isel, Kuang-Yu Chen, Nadia Naffakh
Unité de génétique moléculaire des virus à ARN, Institut Pasteur, CNRS UMR3569, Université de Paris, 28 rue du Docteur Roux, 75015 Paris, France. catherine.isel-griffiths@pasteur.fr kuang-yu.chen@pasteur.fr nadia.naffakh@pasteur.fr
> Les virus influenza, ou virus de la grippe, sont la principale cause des infections respiratoires chez l'homme et constituent un problème de santé publique majeur à l'échelle mondiale [1]. Les virus influenza humains sont responsables d'épidémies saisonnières qui provoquent trois à cinq millions de cas sévères et de 290000 à 650000 décès, selon l'Organisation mondiale de la santé [2]. Des virus influenza d'origine animale peuvent franchir les barrières d'espèce et s'établir dans la population humaine, donnant lieu à des pandémies avec une morbidité et une mortalité accrues. Le génome des virus influenza de type $A$ est constitué de huit segments distincts d'ARN simple brin (appelés ARN viraux ou ARNv) codant chacun au moins une protéine essentielle à la production de virus infectieux. Chaque ARNv est encapsidé par des oligomères de nucléoprotéine (NP) et associé à une polymérase virale, le tout constituant une ribonucléoprotéine virale (RNPv) (Figure IA) [3]. La nature segmentée du génome permet, lors de la co-infection d'une cellule par deux ou plusieurs virus, la production de virus «réassortis», porteurs de nouvelles combinaisons entre ARNv issus des différents virus parentaux, et qui peuvent avoir des propriétés nouvelles et imprévisibles (Figure 1B) [4]. Le réassortiment génétique est un mécanisme majeur d'évolution et d'émergence des virus influenza, et les virus responsables des quatre dernières pandémies (en 1918, 1957, 1968 et 2009) sont issus d'un réassortiment génétique entre des virus influenza de type A humains et aviaires ou porcins $[1,4]$.
Le nombre théorique de génotypes réassortis issus d'une co-infection avec deux virus est de $256\left(2^{8}\right)$, mais une telle diversité n'a jamais été observée in vitro ou in vivo, et certains ARNv co-ségrègent, indiquant que le réassortiment génétique est biaisé. Des incompatibilités entre les ARNv ou entre les protéines des virus parentaux peuvent restreindre la diversité des virus réassortis issus d'une co-infection (Figure IB) [5]. Parmi les incompatibilités entre protéines virales les mieux documentées figurent celles entre les deux glycoprotéines de surface et celles entre les sous-unités de la polymérase virale. La polymérase est un hétérotrimère constitué des protéines $P B 2, P B 1$ et $P A$, qui coopèrent étroitement pour assurer la transcription et la réplication du génome viral dans le noyau des cellules infectées (Figure 1A) [3]. Les résultats de nos travaux récemment publiés dans la revue PLoS Pathogens [6] ont montré que le potentiel de réplication des virus réassortis issus d'une co-infection est contrôlé non seulement par l'efficacité avec laquelle les protéines PB1, PB2 et $P A$ s'assemblent en un hétérotrimère fonctionnel, mais également par le taux de dimérisation de la polymérase.

Notre étude est issue d'une observation fortuite et surprenante: un virus influenza réassorti produit par génétique inverse ${ }^{l}$, dont sept des huit segments génomiques dérivent de la souche $A$ / $\mathrm{PR} / 8 / 34$ (PR8) et dont seul le segment

${ }^{1}$ Génétique inverse : production de virus recombinants à partir d'ADN complémentaires du génome viral, clonés dans des plasmides, puis introduits dans des cellules en culture par transfection transitoire.
PB2 dérive de la souche de laboratoire A/WSN/33 (WSN) (Figure 2A), présente des capacités réplicatives atténuées par rapport au virus PR8 sauvage malgré $97 \%$ d'identité de séquence entre les protéines PR8-PB2 et WSN-PB2. Afin de comprendre les bases moléculaires de cette observation, nous avons effectué des passages en série du virus réassorti atténué PR8 x PB2-WSN et sélectionné des révertants phénotypiques ${ }^{2}$, porteurs de mutations secondaires sur les protéines PB1, PB2 ou PA. Trois constellations distinctes de mutations ont été identifiées par séquençage complet du génome des virus révertants. Étonnamment, chacune des trois comportait une mutation (PA-E349K, PB2-G74R ou PB1-K577G) localisée à l'interface d'un dimère de la polymérase virale, interface mise en évidence par de récentes études structurales (Figure 2B) [7-9]. L'importance fonctionnelle de ce dimère, cependant, n'était pas bien établie. Nous avons donc entrepris de caractériser plus précisément le virus réassorti atténué, les virus révertants et des virus recombinants porteurs d'une ou plusieurs des mutations de réversion secondaires.

Nous avons, dans les cellules infectées, quantifié les $A R N$ viraux, i.e. les ARNv génomiques, mais aussi les ARN complémentaires (ARNC) servant d'intermédiaire de réplication et les ARN messagers $(A R N m)$, par rétro-transcription

\footnotetext{
2 Révertants phénotypiques: virus issus d'un virus initialement atténué, ayant acquis (par exemple au cours d'amplifications en série) des mutations favorables qui améliorent sa capacité de multiplication. Cette dernière peut être évaluée par le titre en particules virales infectieuses produites dans le surnageant des cellules infectées, par exemple.
} 

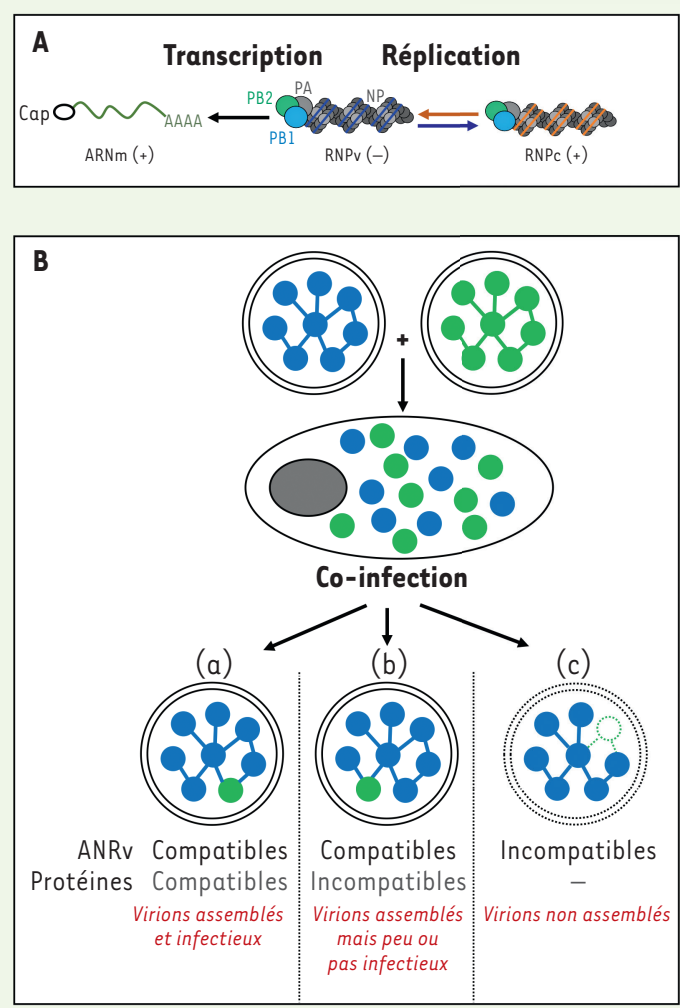

Figure 1. Le génome ARN segmenté des virus influenza leur confère un potentiel de réassortiment génétique. A. Schéma de la structure et de l'activité d'une ribonucléoprotéine virale. Chacun des huit segments génomiques, constitué d'ARN viral simple brin de polarité négative (ARNv), est encapsidé par des oligomères de nucléoprotéine (NP) et associé à une polymérase virale (un hétérotrimère PB1-PB2-PA), le tout constituant une ribonucléoprotéine virale (RNPv). Les RNPv servent de matrice pour la transcription (i.e. la synthèse d'ARN messagers, ARNm) et la réplication du génome (i.e. la synthèse d'un ARN de polarité positive complémentaire de I'ARN génomique, qui forme une RNPc par association avec NP et la polymérase virale, et sert à son tour de matrice pour la synthèse de nouvelles RNPv). Figure adaptée de [5]. B. Réassortiment génétique. Une cellule co-infectée par deux virus influenza distincts (dont les huit segments génomiques sont représentés en bleu ou en vert) produit des virus réassortis, porteurs de nouvelles combinaisons entre ARNv issus des deux virus parentaux. La

diversité des virus réassortis est limitée par des incompatibilités entre les ARNv (certaines combinaisons d'ARNv ne s'assemblent pas correctement pour former un génome complet) et par des incompatibilités entre les protéines virales (certaines combinaisons de protéines ne coopèrent pas efficacement pour assurer la multiplication virale). Figure adaptée de [8].

suivie d'une amplification génique (RT$P C R$ ) (Figure IA). Nous avons également mesuré l'activité de la polymérase virale dans un système de reconstitution de pseudo-RNPv par transfection transitoire, et avons utilisé ce système dit «mini-génome » ${ }^{3}$ pour effectuer des tests de trans-complémentation avec des protéines PB2 mutées, compétentes uniquement pour la transcription ou la réplication du génome viral. L'ensemble des résultats a révélé que la polymérase du virus PR8 $\times$ WSN-PB2 est déficiente dans son activité de réplication, plus particulièrement à l'étape de synthèse des ARNv à partir d'ARNc. L'une

\footnotetext{
3 Système mini-génome: système reposant sur la trans fection transitoire de cellules en culture avec un mélange de plasmides permettant l'expression des protéines virales PB1, PB2, PA et NP et d'un ARN pseudo-viral porteur d'un gène rapporteur (luciférase par exemple). II permet de reconstituer des pseudo-RNPv et d'évaluer l'activité de la polymérase virale en mesurant les niveaux d'activité du gène rapporteur dans les lysats de cellules transfectées.
}

ou l'autre des trois mutations de réversion PA-E349K, PB2-G74R ou PB1-K577G, situées à l'interface de dimérisation de la polymérase virale, suffit à restaurer des niveaux d'activité de la polymérase équivalents à ceux observés pour le virus PR8 sauvage dans le système «mini-génome» (Figure 3A). La mutation PA-\&349K, analysée plus en détail, induit une augmentation significative des niveaux d'ARNv, ARNc et ARNm synthétisés dans le contexte infectieux.

Nous avons alors fait un rapprochement entre nos observations et des données publiées montrant 1) que la synthèse des ARNv à partir d'ARNc nécessite l'intervention d'une polymérase soluble qui trans-active la polymérase associée à I'ARNc matrice [3] ; et 2) que la polymérase virale peut se dimériser voire s'oligomériser [7-9]. Nous avons émis l'hypothèse que le défaut de synthèse de l'ARNv à partir de l'ARNc par la poly- mérase du virus PR8 $\times$ WSN-PB2 était lié à un défaut de dimérisation. Les niveaux de dimérisation de la polymérase ont été mesurés à l'aide d'un test de complémentation entre deux fragments de l'enzyme Gaussia Luciférase (Glucl et Gluc2), qui ne s'associent pas spontanément, mais qui peuvent reconstituer une enzyme luciférase active s'ils sont fusionnés à deux protéines capables de s'associer entre elles [10] (Figure 3B). Nous avons co-exprimé de manière transitoire des protéines de fusion $\mathrm{PB} 1-$ Glucl et PB1-Gluc2, en présence des sous-unités $P B 2$ et $P A$, et en absence ou en présence d'ARNc et de la nucléoprotéine NP (Figure 3B). Contre toute attente, les mesures d'activité de la luciférase indiquent que la polymérase du virus atténué PR8 $\times$ WSN-PB2 présente un niveau de dimérisation égal voire supérieur à celui de la polymérase sauvage constituée des trois sous-uni- 

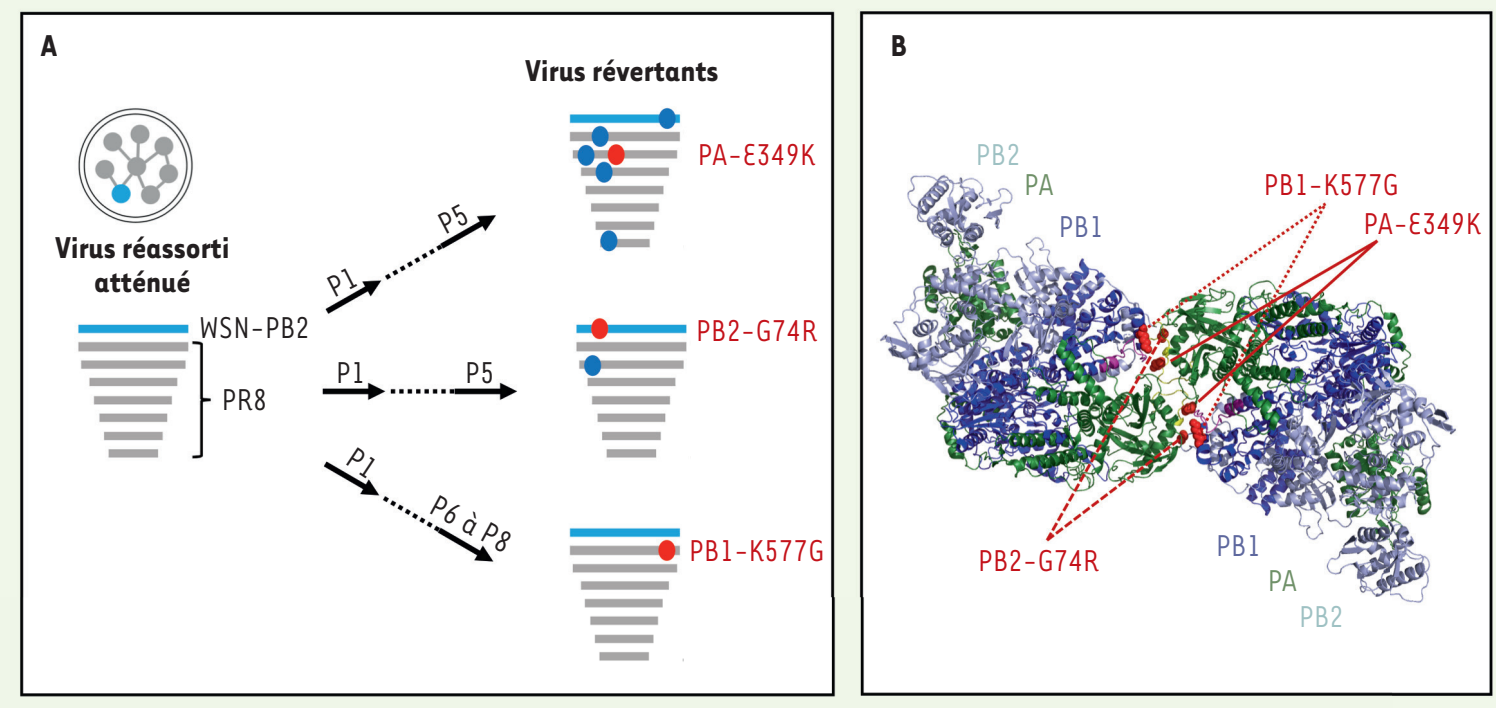

Figure 2. La capacité de réplication du virus réassorti PR8 $\times$ WSN-PB2 est déterminée par des résidus situés à l'interface d'un dimère de polymérase. A. Virus atténué et virus révertants. Les sept segments génomiques dérivés du virus $A / P R / 8 / 34$ sont représentés en gris, et le segment génomique PB2 dérivé du virus A/WSN/33 est représenté en bleu. Les mutations secondaires identifiées dans les virus révertants après séquençage de l'intégralité de leur génome sont représentées par des pastilles bleues, ou par des pastilles rouges lorsqu'il s'agit des résidus situés à l'interface de dimérisation de la polymérase virale. B. Structure cristallographique d’un dimère de la polymérase virale [8]. Les trois résidus situés à l'interface de dimérisation et mutés dans les virus révertants sont indiqués en rouge.
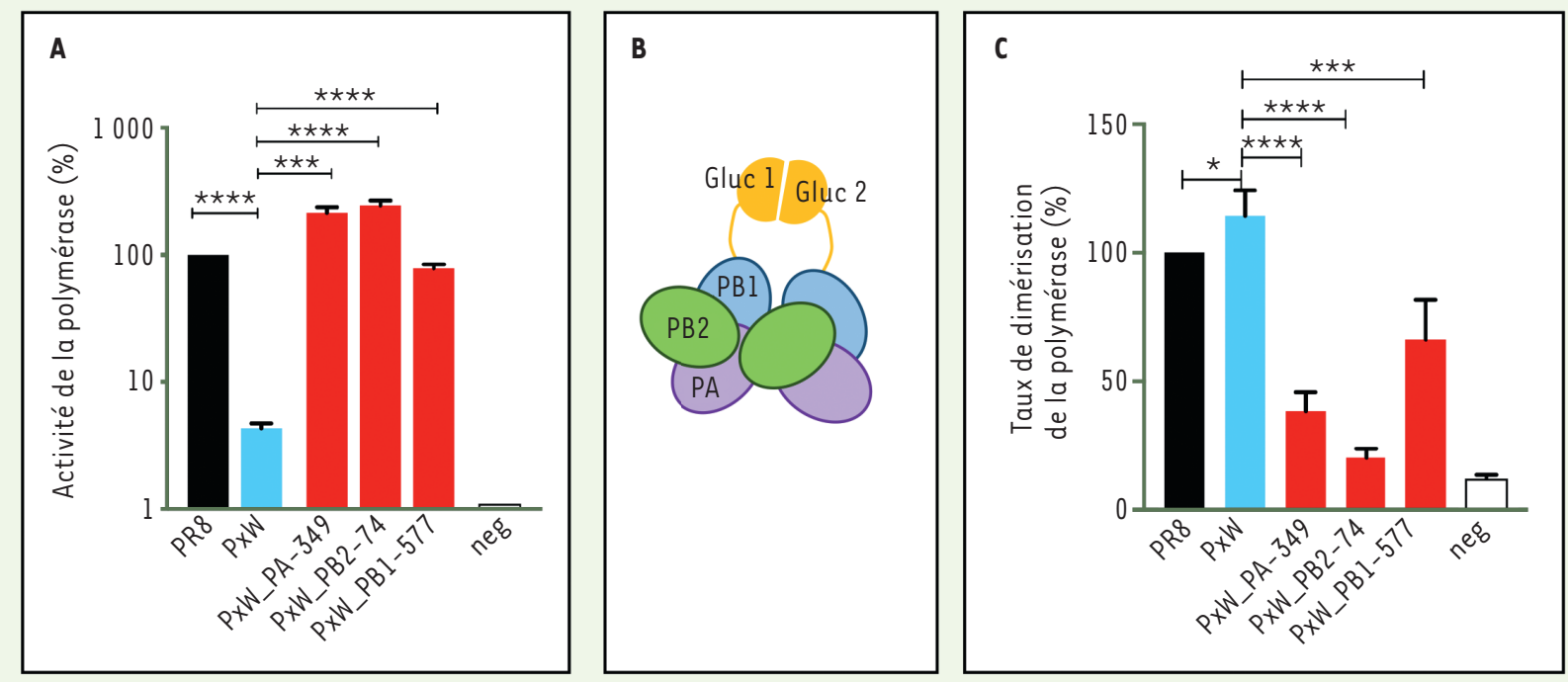

Figure 3. Les mutations de réversion secondaire augmentent l'activité de la polymérase du virus réassorti PR8 $\times$ WSN et réduisent son niveau de dimérisation. A. Effet des mutations secondaires PA- 3349 K, PB2-G74R et PB1-K577G sur l'activité de la polymérase virale du virus réassorti PR8 $\times$ WSN-PB2 (PxW), mesurée dans un test «mini-génome». PR8 : activité polymérase du virus PR8 de type sauvage (témoin positif). Neg: activité de la polymérase mesurée en absence des sous-unités PB2 et PA. $B$. Représentation schématique du test de dimérisation reposant sur la trans-complémentation des deux fragments de l'enzyme Gaussia luciférase (Glucl et Gluc2). C. Effet des mutations secondaires PA-E349K, PB2G74R et PB1-K577G sur le taux de dimérisation de la polymérase virale du virus réassorti PR8 x WSN-PB2 (PxW), mesurée dans le test décrit en B. PR8 : signal luciférase mesuré en présence de la polymérase du virus PR8 de type sauvage (témoin positif). Neg : activité de la polymérase mesurée en absence des sous-unités PB2 et PA (figure adaptée de [6]). 
tés homologues du virus PR8 (Figure 3C). Les mutations de réversion situées à l'interface de dimérisation réduisent le niveau de dimérisation en-dessous de celui mesuré pour la polymérase sauvage (Figure $3 C$ ), selon une tendance inverse à celle observée dans le système «mini-génome » (Figure 3A).

La polymérase des virus influenza est une machine moléculaire d'une grande complexité. Sa capacité à répliquer et transcrire le génome viral selon des mécanismes bien distincts repose à la fois sur la flexibilité conformationelle de l'hétérotrimère et sur sa capacité d'oligomérisation. Nos résultats sont les premiers à établir, dans le contexte infectieux, l'importance fonctionnelle d'une interface de dimérisation révélée par cristallographie, et confortent le modèle selon lequel la formation du dimère active l'étape de synthèse de I'ARNv à partir de I'ARNc. Ils révèlent que le taux de dimérisation optimal varie en fonction du contexte génétique, et qu'un niveau trop élevé peut aboutir à une réplication virale inefficace, ce qui pourrait signifier que le dimère doit être transitoire pour être pleine- ment fonctionnel. Enfin, nos résultats indiquent que les sous-unités de la polymérase grippale co-évoluent pour assurer un niveau approprié de dimérisation entre hétérotrimères, et que ce niveau de dimérisation, s'il n'est pas optimal, est l'un des facteurs pouvant restreindre les possibilités de réassortiment génétique entre virus influenza. Alors que l'arsenal thérapeutique dont nous disposons pour lutter contre les virus influenza reste très insuffisant, le dimère de polymérase apparaît donc comme une nouvelle cible intéressante pour le développement de nouveaux composés anti-viraux. $\diamond$

\section{Dimerisation, a novel feature of the influenza virus RNA polymerase}

\section{REMERCIEMENTS}

Nous remercions $\varepsilon$. Dos Santos Afonso et V. Enouf (Institut Pasteur) pour leur contribution, E. Fodor et J. Grimes (Université d'Oxford) pour leur aide précieuse, R. Fouchier (Erasmus MC) et G. Brownlee (Université d'Oxford), B. Delmas (INRA), S. Munier, S. Behillil, S. van der Werf (Institut Pasteur), et T. Crépin (IBS Grenoble), pour le partage de réactifs et les discussions scientifiques.

\section{LIENS D'INTÉRÊT}

Les auteures déclarent n'avoir aucun lien d'intérêt concernant les données publiées dans cet article.

\section{RÉFÉRENCES}

1. Krammer F, Smith GJD, Fouchier RAM, et al. Influenza. Nat Rev Dis Primers $2018 ; 4: 3$.

2. Organisation Mondiale de la Santé. 2018 ; https:// www.who.int/fr/news-room/fact-sheets/detail/ influenza-(seasonal)

3. Te Velthuis AJ, Fodor $\varepsilon$. Influenza virus RNA polymerase: insights into the mechanisms of viral RNA synthesis. Nat Rev Microbiol 2016 ; 14 : 479-93.

4. Lowen AC. Constraints, drivers, and implications of influenza A virus reassortment. Annu Rev Virol 2017 ; $4: 105-21$.

5. White MC, Lowen AC. Implications of segment mismatch for influenza $A$ virus evolution. J Gen Virol 2018; 99 : 3-16.

6. Chen Ky, Santos Afonso ED, Enouf V, et al. Influenza virus polymerase subunits co-evolve to ensure proper levels of dimerization of the heterotrimer. PLOS Pathog 2019 ; 15 : e1008034.

7. Chang $S$, Sun D, Liang $H$, et al. Cryo-EM structure of influenza virus RNA polymerase complex at $4.3 \AA$ resolution. Mol Cell $2015 ; 57$ : 925-35.

8. Fan H, Walker AP, Carrique L, et al. Structures of influenza A virus RNA polymerase offer insight into viral genome replication. Nature $2019 ; 573: 287-90$.

9. Peng $Q$, Liu Y, Peng $R$, et al. Structural insight into RNA synthesis by influenza $D$ polymerase. Nat Microbiol $2019 ; 4: 1750-9$.

10. Cassonnet P, Rolloy C, Neveu G, et al. Benchmarking a luciferase complementation assay for detecting protein complexes. Nat Methods $2011 ; 8$ : 990-2.

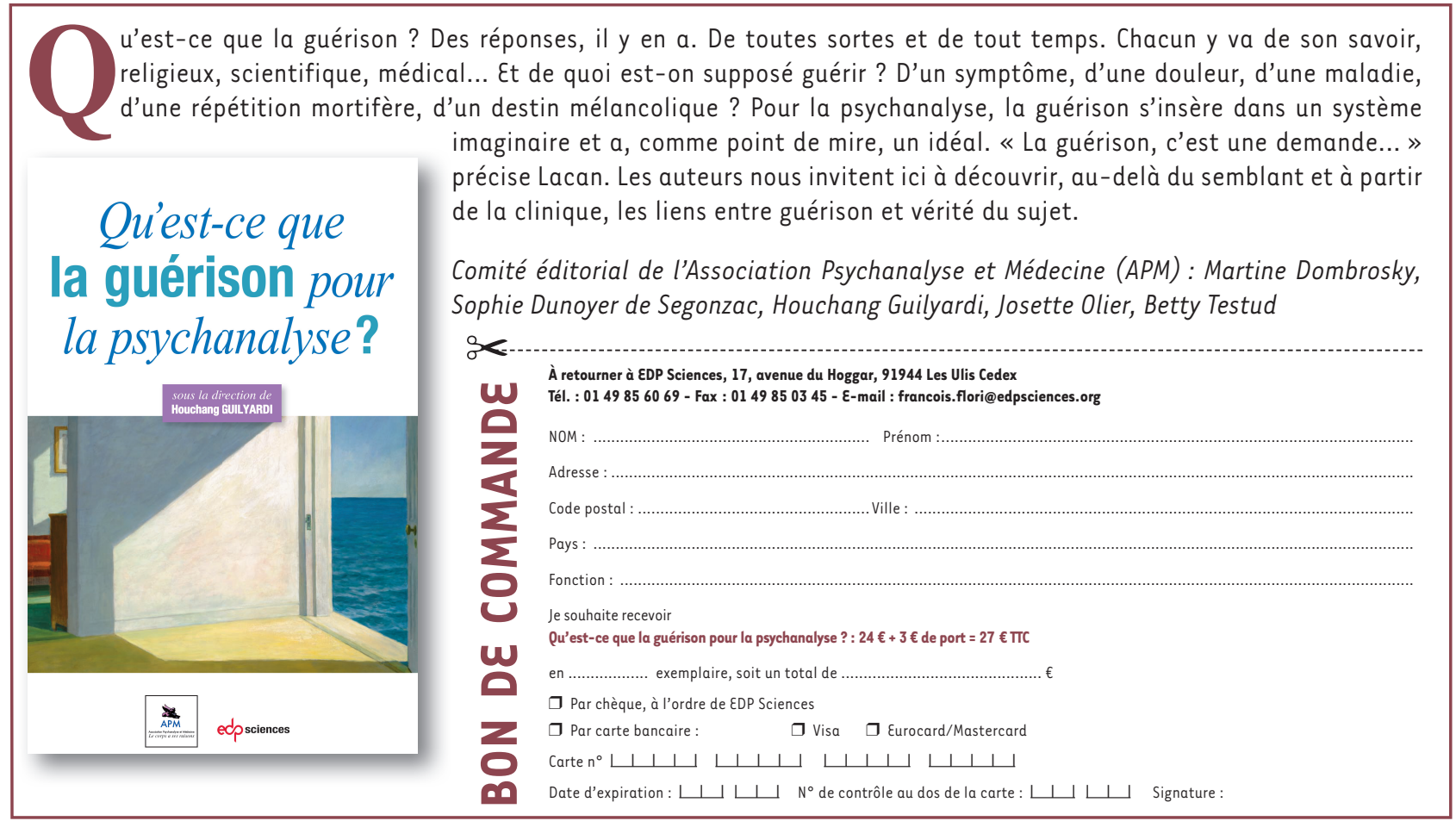

